\title{
Evaluation of Germinal Center-like Structures and B Cell Clonality in Patients with Primary Sjögren Syndrome with and without Lymphoma
}

\author{
Svein Joar Johnsen, Ellen Berget, Malin Viktoria Jonsson, Lars Helgeland, Roald Omdal, \\ and Roland Jonsson
}

\begin{abstract}
Objective. Germinal center (GC)-like structures have previously been observed in minor salivary glands (MSG) of patients with primary Sjögren syndrome (pSS). The aim of our study was to explore the prevalence and features of GC-like structures and B cell clonality in patients with pSS with and without lymphoma.

Methods. Based on a nationwide survey in Norway, we included 21 patients with pSS and with a concomitant lymphoma from whom MSG and/or lymphoma biopsies were available. Tonsil biopsies and MSG from 28 patients with pSS without lymphoma were used as controls. The presence of GC-like structures was investigated with H\&E staining and double staining for CD21/IgD and CD38/IgD. B cell clonality in MSG and tumors were investigated with analysis of immunoglobulin gene rearrangements.

Results. H\&E labeling of MSG revealed GC-like structures in 17/40 (43\%) of the patients: 4/12 (33\%) with and 13/28 (46\%) without lymphoma. Staining for CD21/CD38/IgD demonstrated CD21+ networks in 27/40 (68\%) of the patients. CD21+/CD38-infiltrates were seen in 25/40 (63\%) of the patients, and 16 of these were IgD+ within the infiltrate. Five percent $(2 / 40)$ of the patients presented with CD21+/CD38+ infiltrates resembling tonsillar GC. Monoclonal B cell infiltration in MSG was present in 5/12 patients $(42 \%)$ with and $5 / 28$ patients $(18 \%)$ without lymphoma $(\mathrm{p}=0.12)$. In $2 / 10(20 \%)$ of cases where both MSG and lymphoma biopsies were available, identical clonal rearrangements were detected.

Conclusion. GC-like structures seen in H\&E-stained MSG may represent various subtypes of CD21+ infiltrates. We were unable to detect a clear association between cellular infiltrates, B cell clonality, and lymphoma development. (First Release Oct 1 2014; J Rheumatol 2014;41:2214-22; doi:10.3899/jrheum.131527)
\end{abstract}

Key Indexing Terms: SJÖGREN SYNDROME LYMPHOMA

\author{
SALIVARY GLANDS \\ B LYMPHOCYTES
}

\author{
GERMINAL CENTER \\ CLONAL SELECTION
}

\footnotetext{
From the Clinical Immunology Unit, Department of Internal Medicine, Stavanger University Hospital, Stavanger; Gade Laboratory for Pathology, Department of Clinical Medicine; Section for Oral and Maxillofacial Radiology, Department of Clinical Dentistry; Broegelmann Research Laboratory, Department of Clinical Science; Department of Clinical Science, University of Bergen; Department of Rheumatology, Haukeland University Hospital, Bergen, Norway.

Supported by Folke Hermansen Cancer Research Grant, Broegelmanns Foundation (University of Bergen), the Norwegian Women's Public Health Association, and the Western Norway Regional Health Authority. S.J. Johnsen, MD, Clinical Immunology Unit, Department of Internal Medicine, Stavanger University Hospital; E. Berget, MD; L. Helgeland, $M D, P h D$, The Gade Laboratory for Pathology, Department of Clinical Medicine; M.V. Jonsson, DMD, PhD, Section for Oral and Maxillofacial Radiology, Department of Clinical Dentistry, Broegelmann Research Laboratory, Department of Clinical Science; R. Omdal, MD, PhD, Department of Clinical Science, University of Bergen; R. Jonsson, DMD, PhD, Broegelmann Research Laboratory, Department of Clinical Science, Haukeland University Hospital, Department of Rheumatology.

Address correspondence to Dr. S.J.A. Johnsen, Clinical Immunology Unit, Department of Internal Medicine, Stavanger University Hospital, P.O. Box 8100, N-4068 Stavanger, Norway.E-mail: josj@sus.no Accepted for publication July 24, 2014.
}

Primary Sjögren syndrome (pSS) is a chronic autoimmune exocrinopathy histopathologically characterized by mononuclear cellular infiltration and destruction, mainly of the salivary and lacrimal glands. In most patients, this leads to reduced saliva and tear production, with subsequent oral and ocular dryness phenomena (xerostomia and keratoconjunctivitis sicca). Extraglandular manifestations such as myalgia, arthralgia, and fatigue are common, and immunological disturbances in terms of hypergammaglobulinemia, rheumatoid factor, and autoantibodies against the ribonucleosides SSA/Ro and SSB/La are frequently encountered $^{1}$, and even seem to be present long before symptom onset $^{2}$. The pathogenesis of pSS is largely unknown. Associations to MHC genes and non-MHC genes important for immune, inflammation, and regulatory functions have been demonstrated ${ }^{3,4,5}$, and an interaction between genetic predisposition and unknown environmental factors are thought to represent the necessary players for the devel- 
opment of disease. A strong interferon signature is present in a substantial number of patients with $\mathrm{pSS}^{6}$.

The cellular infiltrates in pSS salivary glands reportedly consist of $\mathrm{T}, \mathrm{B}$, and plasma cells, macrophages, and follicular dendritic cells ${ }^{7}$, and seem to be stable over time ${ }^{8}$. Ectopic germinal center (GC)-like structures can be observed in H\&E-stained minor salivary gland (MSG) sections in $20-30 \%$ of patients with $\operatorname{pSS}^{9}$. The presence of GC-like structures seems to distinguish a distinct disease phenotype ${ }^{10,11,12,13}$, and GC formation has recently been suggested as a predictor for lymphoma development ${ }^{14}$. Additional staining for the CD21 marker to detect follicular dendritic cell (FDC) networks has been widely applied in evaluation of GC-like structures ${ }^{7,12,15,16}$, and the CD38 marker has been used to detect GC B cells ${ }^{17,18}$. Expression of activation-induced cytidine deaminase (AID) has been demonstrated in GC-like structures by immunohistochemical staining and quantitative real-time $\mathrm{PCR}^{15,16}$, suggesting functionality. In addition, the marker CD38 seemed to differentiate AID-expressing versus non-AID-expressing infiltrates ${ }^{16}$. GC-like structures are also known as "tertiary lymphoid organs", and an analog lymphoid organization is seen in target organs of patients with other autoimmune diseases ${ }^{19}$. Criteria for the term "tertiary lymphoid organs" have been suggested ${ }^{20}$, but no consensus has been reached about the term "GC-like structures" in rheumatology. In addition, mechanisms leading to formation of GC-like structures or their role in autoimmune disease pathogenesis are not entirely clear $9,15,16,21,22$.

There is a 6.5 to 15.6 -fold increased risk for non-Hodgkin lymphomas in $\mathrm{pSS}^{23,24,25}$, the most common lymphoma (MZL) subtype being extranodal marginal zone lymphoma of the mucosa-associated lymphoid tissue $(\text { MALT })^{26}$. MALT lymphomas are distinct neoplasms that arise extranodally in the setting of chronic inflammatory disorders $^{27}$. The malignant cells originate from B cells in the marginal zone of $\mathrm{GC}^{28}$. The current understanding is that the development of MALT lymphoma is antigen driven, and that the nuclear factor $-\kappa \mathrm{B}(\mathrm{NF}-\kappa \mathrm{B})$ pathway seems to play a central role in this concept ${ }^{29}$. Four specific chromosomal translocations have been described in MALT lymphomas, which all lead to aberrant NF- $\mathrm{BB}$ activation ${ }^{28}$. Primary SS lymphomas and salivary gland MALT lymphomas, in general, rarely present with any of these translocations ${ }^{30}$, but seem to harbor various genomic alterations that could interact with other genes modulating the $\mathrm{NF}-\kappa \mathrm{B}$ pathway ${ }^{31,32}$. Recently, an association between antibody-positive pSS and genes in the NF- $\mathrm{KB}$ pathway was demonstrated ${ }^{33}$.

The aim of our study was to evaluate the possible difference between patients with pSS with and without lymphoma regarding $\mathrm{B}$ cell clonality, and prevalence and features of GC-like structures.

\section{MATERIALS AND METHODS}

Patients and controls. Based on data from the Cancer Registry of Norway $^{34}$, we performed a retrospective nationwide search for patients with a combination of pSS and lymphoma. For inclusion, patients had to fulfill the American-European Consensus Criteria for $\mathrm{pSS}^{35}$, and at least 1 formalin-fixed and paraffin-embedded tissue block of either a lymphoma or a MSG biopsy had to be available. Because patients with pSS sometimes have a long period with vague and weak symptoms delaying the diagnosis, patients who developed lymphoma prior to or simultaneously with the establishment of the pSS diagnosis were included in our study.

We identified 33 patients with pSS who had been diagnosed with a lymphoma between January 1, 1986, and December 31, 2012. Of these, 21 patients had tissue blocks available for further study: 10 patients with both lymphoma and MSG tissue blocks, 9 patients with lymphoma tissue blocks, and 2 patients with MSG tissue blocks only. Two patients had tissue blocks from sequential lymphomas, leaving 21 lymphomas and 12 MSG tissue blocks available for study. Because of changing nomenclature and criteria over time, histopathological sections were reexamined and reclassified according to standard protocols for present lymphoma classification (Supplementary Table 1, available from authors on request).

Twenty-eight MSG biopsies from patients with pSS without lymphoma, matched for sex and age at the time of the biopsy, were provided from the biobank at Stavanger University Hospital for controls. To evaluate the staining pattern in secondary lymphoid tissue, tonsil tissue sections from subjects undergoing tonsillectomy because of other medical indications but without known malignancy or autoimmune diseases were provided from the department of Otolaryngology, Head and Neck Surgery, Haukeland University Hospital, Bergen.

Formalin-fixed, paraffin-embedded tissue sections. Lymphoma, MSG, and tonsil tissue blocks were cut in $3-\mu \mathrm{m}$ slices using a microtome (Leica Instruments $\mathrm{GmbH}$ ) and placed onto SuperFrost Plus microscope slides (Menzel GmbH and Co.).

Immunohistochemical staining of lymphomas. Following de-paraffinization, rehydration, and heat-induced epitope retrieval, tissue sections were incubated with primary antibodies [CD3, CD20, CD21, CD79a, Ki-67, BCL2, BCL6, $\lambda$, and $\kappa$ (Dako); CD2, CD5, CD10, CD23, and PAX5 (Novocastra, Leica Biosystems); CD138 and CyclinD1 (NeoMarkers); Foxp3 (BD Biosciences); EBER (Roche); BOB1a and OCT2 (Santa Cruz Biotech)] using the Dako EnVision Autostainer system (Dako). Staining with CD3, CD20, and Ki-67 was performed with the Ventana Medical Systems Stainer, and EBER staining with the Ventana's OptiView DAB IHC Detection Kit (Ventana).

Double-labeling of MSG sections with CD21/IgD and CD38/IgD. Immunohistochemical double staining of consecutive MSG and tonsil sections was performed with $\mathrm{CD} 21 / \mathrm{IgD}$ and $\mathrm{CD} 38 / \mathrm{IgD}$ using the Dako EnVision Doublestain System as described by the manufacturer. All sections were de-paraffinized and rehydrated overnight, followed by heat-induced epitope retrieval (Dako PT-link) and incubation with endogenous enzyme block for $10 \mathrm{~min}$. Sections were then incubated with the first primary antibody, monoclonal mouse anti-human CD21 (Dako) diluted 1:15 or CD38 (Novocastra) diluted 1:50 for $60 \mathrm{~min}$, before incubation with the second primary antibody, polyclonal rabbit anti-human $\operatorname{IgD}$ (Dako) diluted 1:2 for $60 \mathrm{~min}$. The sections were then incubated for 30 min with anti-rabbit/mouse polymer AP link (Dako), Liquid Permanent Red $10 \mu \mathrm{l} / \mathrm{ml}$ buffer for $10 \mathrm{~min}$, and then washed with water for $5 \mathrm{~min}$. After counterstaining with hematoxylin for $10 \mathrm{~min}$ and a final wash in water, the sections were dehydrated through ethanol and xylene for $5 \mathrm{~min}$ and mounted with Eukitt.

Evaluation of staining patterns. Sections were evaluated using a light microscope. All the H\&E-stained MSG were assessed for GC-like structures, defined as a well-circumscribed chronic cellular infiltration consisting of $\geq 50$ mononuclear cells with features indicating lymphoid organization and morphology resembling a dark zone, and a light zone within otherwise normal salivary gland epithelium ${ }^{13,14}$.

Personal non-commercial use only. The Journal of Rheumatology Copyright $@$ $\odot 2014$. All rights reserved. 
Table 1. Baseline characteristics for patients with pSS with and without lymphoma.

\begin{tabular}{lcccc}
\hline Characteristics & $\begin{array}{c}\text { Patients without } \\
\text { Lymphoma, } \mathrm{n}=28\end{array}$ & $\begin{array}{c}\text { Patients with } \\
\text { Lymphoma, } \mathrm{n}=21\end{array}$ & $\begin{array}{c}\text { All Patients, } \\
\mathrm{n}=49\end{array}$ & $\mathrm{p}$ \\
\hline Age, yrs, at pSS diagnosis, median (range) & $52(34-85)$ & $51(29-78)$ & $51(29-85)$ & $\mathrm{NS}$ \\
Disease duration, yrs, median (range) & $10(5-23)$ & $13(2-36)$ & $10(2-36)$ & $\mathrm{NS}$ \\
Age lymphoma diagnosis, yrs, median (range) & - & $53(31-78)$ & - & - \\
Female sex, n (\%) & $23(82)$ & $19(91)$ & $42(86)$ & $\mathrm{NS}$ \\
Anti-SSA and/or anti-SSB antibodies (\%) & $25 / 28(89)$ & $17 / 21(81)$ & $42 / 49(86)$ & $\mathrm{NS}$ \\
Symptoms of ocular dryness (\%) & $20 / 27(74)$ & $21 / 21(100)$ & $41 / 48(85)$ & 0.01 \\
Symptoms of oral dryness (\%) & $25 / 27(93)$ & $20 / 21(95)$ & $45 / 48(94)$ & $\mathrm{NS}$ \\
Reduced tear flow* (\%) & $21 / 27(78)$ & $11 / 12(92)$ & $32 / 39(82)$ & $\mathrm{NS}$ \\
Reduced unstimulated salivary flow (\%) & $19 / 26(73)$ & $8 / 11(73)$ & $27 / 37(73)$ & $\mathrm{NS}$ \\
Minor salivary gland Focus Score $\geq 1(\%)$ & $21 / 28(75)$ & $17 / 17(100)$ & $38 / 45(84)$ & 0.03 \\
Focus score, median (range) & $1.1(0-10.0)$ & $2.0(1.0-5.0)$ & $2.0(0-10.0)$ & 0.03 \\
\hline
\end{tabular}

*Tested with Schirmer test $(<5 \mathrm{~mm} / 5 \mathrm{~min})$. Categorical variables were analyzed by Fisher's exact test and continuous variables by the Mann-Whitney U test. pSS: primary Sjögren syndrome; NS: not significant.

The tonsil tissue sections were used as a positive control for the double-staining. The CD21/IgD-stained sections were assessed for a $\mathrm{CD} 21+$ network-like staining pattern in the presence of a surrounding $\operatorname{IgD}+$ mantle zone, and the CD38/IgD-stained sections for a localized cellular aggregate containing CD38+ B cells and surrounded by an IgD+ mantle zone. Other IgD-staining patterns, such as scattered positive cells within infiltrates and single-positive cells in small interstitial cell clusters related to glandular epithelial cells, were also noted. An overall evaluation was performed by assessing the double-stainings, and to categorize the staining patterns into 3 groups termed nonspecific (CD21-/CD38-/IgD-), focal cellular infiltrates (CD21+/CD38- networks), or partially characterized GC (CD21+/CD38+ networks), similar to secondary lymphoid tissue from tonsillar tissue sections. All lymphoma sections were examined by LH and SJJ. MSG sections were blindly read by MVJ and SJJ, reaching agreement in $116 / 120$ cases. The remaining 4 cases were discussed with a senior author (RJ) and a final decision was reached.

DNA extraction. Three $10-\mu \mathrm{m}$ sections were cut from all available MSG and lymphoma biopsies, and the sections de-paraffinized with xylene, dehydrated in $100 \%$ ethanol, and set for overnight proteinase $\mathrm{K}(20 \mathrm{mg} / \mathrm{ml})$ digestion. DNA was prepared manually using the E.N.Z.A Tissue DNA kit according to the manufacturer's instructions (Omega Bio-Tek).

PCR analysis of B cell clonality. The multiplex PCR kit (catalogue no. 206143, Qiagen) with HotStarTaq DNA polymerase was used for the clonality analysis. Five BIOMED-2 primer sets including immunoglobulin heavy chain $\mathrm{VH}-\mathrm{JH}$ ( $\mathrm{Fr} 1, \mathrm{Fr} 2$, and $\mathrm{Fr} 3$ ), immunoglobulin light chain VK-JK, and $\kappa$ deleting element were run separately ${ }^{36}$. We used a modified BIOMED-2 protocol, mixing $2.5 \mu \mathrm{l}$ DNA template, $2.5 \mu \mathrm{l}$ primer mix (2 $\mu \mathrm{m}$ of each primer), $12.5 \mu \mathrm{l}$ Multiplex buffer, and $7.5 \mu \mathrm{l}$ water to a final reaction volume of $25 \mu \mathrm{l}^{37}$. All samples were run with undiluted and 5-fold diluted template DNA, and monoclonal, polyclonal, and nontemplate controls were included in all runs. The PCR conditions included an initial activation step $\left(95^{\circ} \mathrm{C}, 15 \mathrm{~min}\right)$, followed by 38 cycles consisting of denaturation $\left(95^{\circ} \mathrm{C}, 45 \mathrm{~s}\right)$, annealing of primers $\left(60^{\circ} \mathrm{C}, 90 \mathrm{~s}\right)$, and extension $\left(72^{\circ} \mathrm{C}, 90 \mathrm{~s}\right)$, before a final extension step $\left(70^{\circ} \mathrm{C}, 10 \mathrm{~min}\right)$ followed by cooling to $4^{\circ} \mathrm{C}^{37}$.

Assessment of B cell clonality. Fragment analyses of the PCR products were performed using Applied Biosystems PRISM 3100 capillary sequencer (Applied Biosystems). Identification of 1 or 2 peaks within expected range consistent after dilution was interpreted as clonal. All samples were assessed for clonality by $\mathrm{LH}$ and $\mathrm{EB}$, and a consensus was established.

Statistical analyses. Non-parametric statistics were used, and groups were compared with the Mann-Whitney U test for continuous variables, Fisher's exact test for categorical variables, and the Freeman-Halton extension for a $4 \times 2$ contingency table.

Ethics and approval. The Regional Committee for Medical and Health Research Ethics approved our study (REK Vest 2009-250/17, 2009-250/18).

\section{RESULTS}

Patients. The baseline characteristics of the patients with pSS with $(n=21)$ and without $(n=28)$ lymphoma are shown in Table 1. Controls were selected to match the age and sex of the patients with lymphoma, hence the groups were similar regarding age, disease duration, and sex. However, the patients with lymphoma were more likely to have a positive MSG biopsy and had higher focus score. The median time between pSS diagnosis and lymphoma development was 15 months, and the range was from 240 months before the pSS diagnosis to 224 months after the pSS diagnosis. Four patients (19\%) were diagnosed with lymphoma before pSS, 5 patients (24\%) had both conditions diagnosed at the same time ( $\pm 6 \mathrm{mos})$, and $12(57 \%)$ were diagnosed with lymphoma after pSS.

Reclassification of the lymphomas showed that the majority of patients $(71 \%)$ had an MZL (Table 2). One patient had a nodal MZL, and all the remaining were extranodal MZL (67\%). The majority (62\%) of the MZL was of the MALT subtype and was located in the salivary glands $(52 \%)$. Details of lymphoma subtypes and localization are given in Table 2. Finally, 2 of the lymphoma blocks (1 bone marrow biopsy and 1 pulmonary fine needle aspiration) did not contain enough material for a full reclassification.

Immunohistochemical staining. In the H\&E-stained MSG sections, GC-like structures (Figure 1A-B) were seen in $17 / 40(43 \%)$ of the patients: $4 / 12(33 \%)$ of the patients with lymphoma and $13 / 28(46 \%)$ of the patients without lymphoma, respectively (Figure 2A). There was no signifi-

Personal non-commercial use only. The Journal of Rheumatology Copyright @ 2014 . All rights reserved. 
Table 2. Overview of lymphoma types, subtypes, localization, and detection of immunoglobulin gene rearrangements.

\begin{tabular}{|c|c|c|c|c|}
\hline Type & Subtype & Localization & Total, $\mathrm{n}(\%), \mathrm{n}=21$ & Monoclonality (\%) \\
\hline \multirow[t]{5}{*}{ MZL } & & & $15(71)$ & $12 / 15(80)$ \\
\hline & Nodal MZL & & $1(5)$ & $1 / 1(100)$ \\
\hline & & Bone marrow & $1(5)^{*}$ & $1 / 1(100)$ \\
\hline & MALT lymphoma & & $13(62)$ & $10 / 13(77)$ \\
\hline & & Salivary glands & $11(52)$ & $9 / 11(82)$ \\
\hline \multirow[t]{3}{*}{ Diffuse large cell B cell lymphoma } & & & $3(14)$ & $3 / 3(100)$ \\
\hline & & Lymph node & $1(5)$ & $1 / 1(100)$ \\
\hline & & Salivary glands & $2(10)$ & $2 / 2(100)$ \\
\hline Hodgkin lymphoma (nodular sclerosis) & & Lymph node & $1(5)$ & $0 / 1(0)$ \\
\hline Chronic lymphocytic leukemia & & Bone marrow & $1(5)^{*}$ & $1 / 1(100)$ \\
\hline Not classified & & & $2(10)$ & $0 / 2(0)$ \\
\hline
\end{tabular}

*One patient had 2 lymphoma subtypes in the bone marrow. MZL: marginal zone lymphoma; MALT: mucosa-associated lymphoid tissue.

cant difference in frequency of GC-like structures in the $\mathrm{H} \& \mathrm{E}-$ stained sections between the groups $(\mathrm{p}=0.51)$.

The double-staining with $\mathrm{CD} 21 / \mathrm{IgD}$ demonstrated CD21+ networks in 27/40 of the patients (68\%), and both markers were negative in the remaining $13 / 40$ patients (33\%). CD21+ networks were detected in $16 / 17$ of the patients (94\%) with GC-like structures seen in the H\&E-staining sections. Three different IgD-staining patterns were seen in the CD21+ tissue sections: 16/40 of the patients $(40 \%)$ presented with colocalization of IgD+ cells and CD21+ networks, 10/40 (25\%) were completely IgD-, and in 1 patient the $\mathrm{CD} 21+$ networks resided within surrounding $\mathrm{IgD}+$ mantle zones. $\mathrm{CD} 21+$ networks were seen in $7 / 12$ of patients with lymphoma (58\%) and 20/28 of patients without lymphoma (71\%; Figure 2B), but this difference was not significant ( $\mathrm{p}=0.48$ ).

The CD38/IgD double-staining showed CD38- infiltrates in 38/40 (95\%) of the patients. A cluster of CD38+ B cells with GC-like appearance was seen in only $2 / 40$ of the patients (5\%), and 1 of these revealed an IgD+ mantle zone. Both patients with a CD38+ infiltrate were in the group without lymphoma ( $\mathrm{p}=0.08)$.

An overall evaluation of the double-labeling demonstrated CD21+ networks in 27/40 (68\%) of the patients; CD21+/CD38+ partially characterized GC were found in 2/40 of the patients (5\%; Figure 1E-F); CD21+/CD38- focal cellular infiltrates (Figure 1G-H) were seen in $25 / 40$ of the patients (63\%); and in 16/40 of the patients (40\%), the CD21+ infiltrates were IgD+. The remaining $13 / 40$ of the patients (33\%) presented with nonspecific staining pattern within cellular infiltrates (CD21-/CD38-/IgD-). The difference in the distribution of subtypes of infiltrates was not significant between the groups $(p=0.40$; Figure $2 \mathrm{C}$ ), but there was a highly significant association between GC-like structures in the H\&E-stained sections and CD21+ FDC networks in the double-stained sections ( $p=0.002$; Figure $2 D)$.
Detection of B cell clonality. The PCR analyses revealed monoclonal B cell infiltration more frequently in MSG of patients with pSS with lymphoma 5/12 (42\%) compared to patients with pSS without lymphoma 5/28 (18\%), but this difference was not statistically significant ( $\mathrm{p}=0.12$; Figure $3)$. There was no association between presence of monoclonal B cell infiltration and GC-like structures or CD21+ networks in MSG in any of the patient groups.

Monoclonal B cell infiltration was detected in $15 / 21$ of all the lymphomas (71\%), and in $11 / 13$ of the lymphomas $(87 \%)$ located in the salivary glands. In the patients with a history of a lymphoma, there was no significant difference in the frequency of monoclonal B cell infiltration between the lymphoid tumors and the MSG $(\mathrm{p}=0.14)$. In 10 patients where both lymphoma and MSG tissue were available, monoclonal B cell infiltration was detected in 3 of the patients (30\%), and the PCR analysis showed identical sized clonal rearrangements suggestive of identical B cell clones in 2 of these (20\%). Both of these lymphomas were MZL: 1 salivary gland MALT, and 1 nodal MZL.

\section{DISCUSSION}

In the investigated cohort of patients with pSS with and without lymphoma, GC-like structures were observed at similar levels in the H\&E-stained MSG tissue sections, but the $\mathrm{CD} 21 / \mathrm{CD} 38 / \mathrm{IgD}$ labeling showed that the majority of the cellular infiltrates had other immunohistochemical characteristics as compared to tonsillar GC. There was a strong association between the observation of GC-like structures in H\&E-stained sections and CD21+ networks in the double-stained sections. As previously described, the CD21+ infiltrates seem to encompass various different staining patterns ${ }^{7}$ that cannot be identified in the $\mathrm{H} \& \mathrm{E}$ staining. GC-like structures or CD21+ infiltrates were not seen more frequently in the group with lymphoma, but were frequent in both groups. We found a trend toward an

Personal non-commercial use only. The Journal of Rheumatology Copyright ( 2014. All rights reserved. 

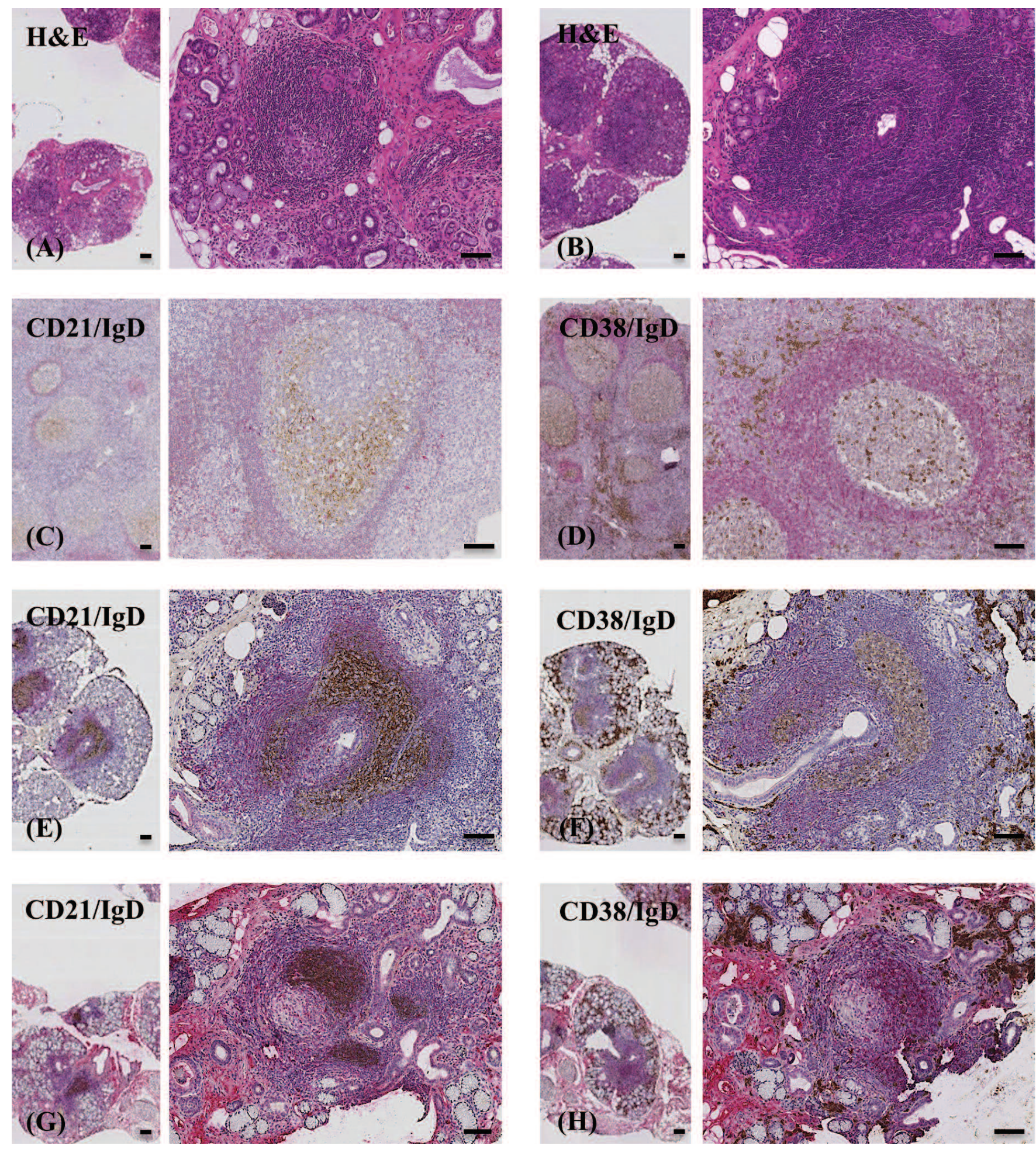

Figure 1. Minor salivary gland H\&E staining and immunohistochemical double-staining with CD21/IgD and CD38/IgD. H\&E staining demonstrated GC-like structures (A, B), but the H\&E staining did not discriminate between various phenotypic subtypes of infiltrates. In tonsil sections, GC stained positive for CD21 (C) and CD38 (D), and the surrounding mantle zone stained positive for IgD. Similar staining patterns were also seen in a minority of the MSG, with $\mathrm{CD} 21+$ (E) and CD38+ (F) GC-like structures surrounded by an IgD+ mantle zone. In the majority of patients, the double-staining showed a different staining pattern, with $\mathrm{CD} 21+(\mathrm{G})$ and $\mathrm{CD} 38-(\mathrm{H})$ lymphocytic infiltrations without a surrounding IgD+ mantle zone. In many of the patients, the CD21+ infiltrates also stained IgD+ within the infiltrate $(\mathrm{H})$. Inserter bar indicates $100 \mu \mathrm{m}$. GC: germinal centers; MSG: minor salivary glands. 

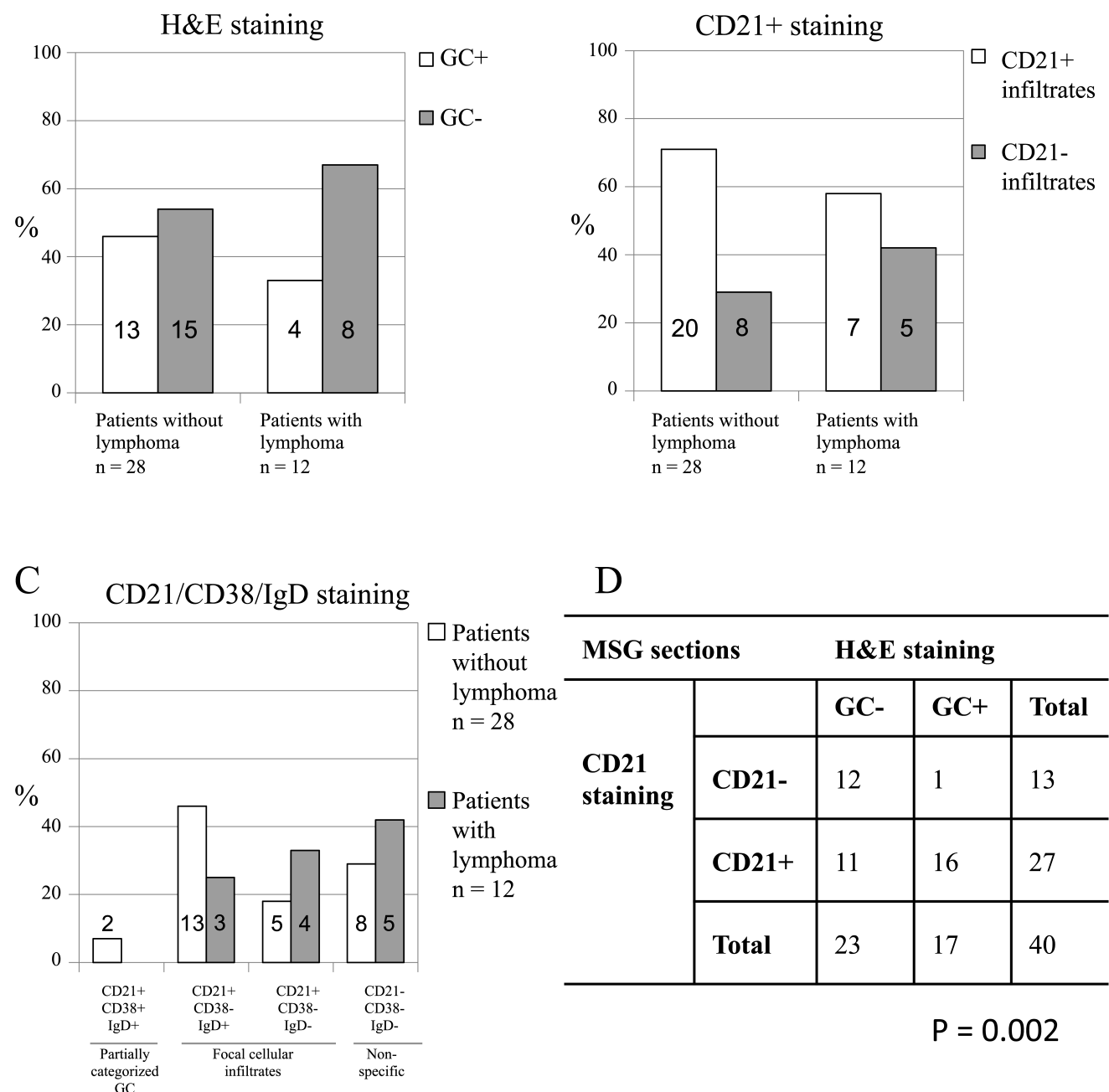

$\mathrm{D}$

\begin{tabular}{|c|c|c|c|c|c|}
\hline \multirow{2}{*}{$\begin{array}{l}\square \text { Patients } \\
\text { without } \\
\text { lymphoma } \\
\mathrm{n}=28\end{array}$} & \multicolumn{2}{|c|}{ MSG sections } & \multicolumn{3}{|c|}{ H\&E staining } \\
\hline & \multirow{4}{*}{$\begin{array}{l}\text { CD21 } \\
\text { staining }\end{array}$} & & GC- & GC+ & Total \\
\hline \multirow{3}{*}{$\begin{array}{l}\square \text { Patients } \\
\text { with } \\
\text { lymphoma } \\
\mathrm{n}=12\end{array}$} & & CD21- & 12 & 1 & 13 \\
\hline & & CD21+ & 11 & 16 & 27 \\
\hline & & Total & 23 & 17 & 40 \\
\hline
\end{tabular}

Figure 2. (A) H\&E staining demonstrated no significant difference in distribution of GC-like structures in MSG of patients with and without lymphoma $(\mathrm{p}=0.51)$. (B) Double-staining with CD21 and IgD showed that the majority of patients had CD21+ FDC networks, but regarding the presence of CD21+ networks, there was no significant difference between the patients with and without lymphoma $(\mathrm{p}=0.48)$. (C) The majority of patients presented CD21+/CD38focal cellular infiltrates, and most of these stained IgD+ within the infiltrate. Only 2 patients presented with CD21+/CD38+ infiltrates, similar to secondary lymphoid tissue GC. (D) A significant association was seen between GC-like structures observed in H\&E-stained sections and CD21+ networks in the double-stained section $(\mathrm{p}=0.002)$. The comparison was performed using Fisher's exact test. GC: germinal center; FDC: follicular dendritic cell; MSG: minor salivary glands.

increased frequency of monoclonal B cellular infiltration in the group of patients with lymphoma. We also detected identical B cell clones in tissue sections from both MSG and lymphoid tumors in 2 patients with MALT lymphoma; this finding supports the hypothesis that development of lymphoproliferative disease in pSS is antigen-driven ${ }^{38}$.

Inflammatory cellular infiltrates and infiltrates with morphological features similar to lymphoid GC have previ- ously been observed in the MSG tissue in patients with pSS and extensively studied ${ }^{7,9,10,11,12,13,14,15,16,39}$. Based on expression of AID and immunohistochemical staining, a further dichotomization between real GC and cellular aggregates has been suggested ${ }^{16}$. In our study, with a few selected markers, only a minority of the MSG cellular infiltrations seem to contain all the selected phenotypic and structural elements from a secondary lymphoid GC. The majority of

Personal non-commercial use only. The Journal of Rheumatology Copyright @ 2014 . All rights reserved. 


\section{Immunoglobulin gene rearrangements analyses}

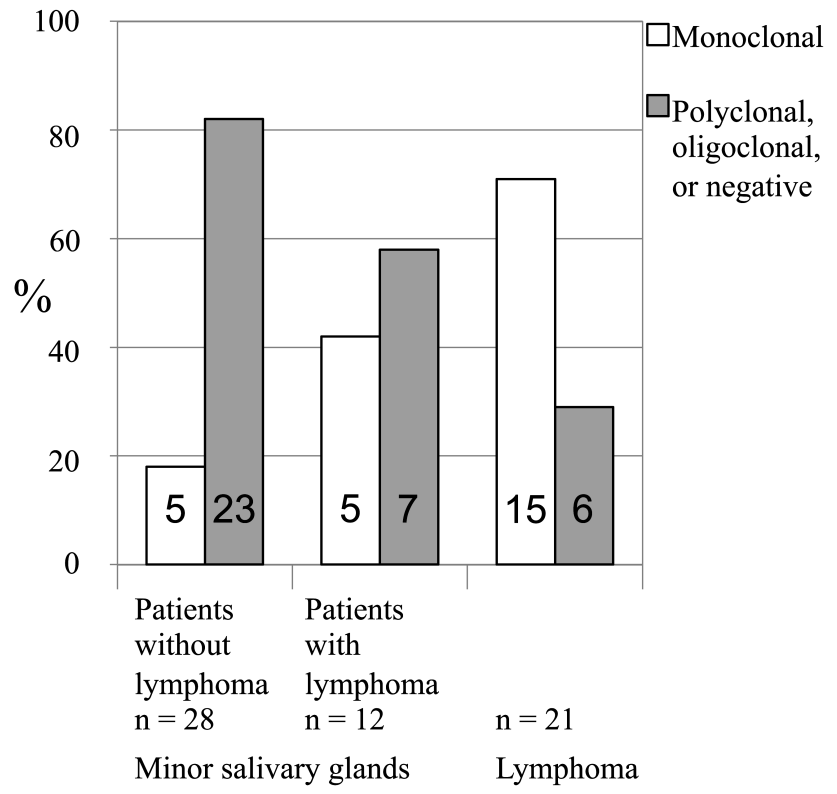

Figure 3. Immunoglobulin gene rearrangements analyses of labial MSG and lymphomas showed that monoclonal B cell infiltrations in MSG were seen more frequently in the group with lymphoma compared to the group without lymphoma, but this difference was not significant $(p=0.12)$. In patients with lymphoma, no significant differences in frequency of monoclonal B cell infiltration were seen between lymphoma tumors and MSG ( $\mathrm{p}=0.14)$. The comparison between the groups was performed using Fisher's exact test. MSG: minor salivary glands.

the focal mononuclear infiltrates contained CD21+ networks, colocalized within a cluster of IgD+ cells, but lacking an IgD+ mantle zone. These focal cellular infiltrates seem similar to the non-AID-expressing cellular infiltrates previously described ${ }^{16,40}$. There was a strong association between GC-like structures and CD21+ networks, but the CD21+ infiltrates seem to include several staining patterns. This finding implies that the GC-like structures seen in H\&E-stained MSG sections, in fact, could represent at least 3 different phenotypes of infiltrates. Because of the study design, clinical implications or relevance of such a subclassification was not investigated.

The majority of the lymphomas (62\%) were located in the salivary glands, and monoclonal B cells were observed in $85 \%$ of lymphomas located in salivary glands. In some lymphomas, no monoclonal B cell infiltration was detected, and possible explanations for this could be DNA degradation, DNA taken from the periphery or outside the actual tumor, or mutations that led to a lack of sufficient primer coverage. Monoclonal B cell infiltrations have previously been described in MSG of patients with pSS without lymphoma ${ }^{41,42}$, and are not considered a valuable predictor for lymphoma development ${ }^{43}$. Our study showed a trend toward a higher frequency of monoclonal B cell infiltration in MSG of patients with a history of lymphoma. In line with previous findings, identical B cell clones were also detected in the MSG and lymphoma tissue biopsies in $20 \%$ of the patients where both tissues were available ${ }^{44,45}$. This result supports the idea that the lymphoma development is antigen-driven ${ }^{38}$, but the antigen driving the clonal selection remains unknown. It has been shown that malignant B cells in pSS express rheumatoid factor specificity, but without binding self-antigens ${ }^{46}$. A recent study suggested an association between an active Epstein-Barr virus infection and formation of GC-like structures in MSG of patients with $\mathrm{pSS}^{47}$, in accordance with current opinion that chronic immune stimulation is a possible mechanism for pSS lymphoma development ${ }^{27}$.

A limitation of our study is the sample size. Based on the prevalence of lymphoma in pSS in Norway, we expected to identify 35 patients with pSS and lymphoma ${ }^{24}$; hence the numbers of patients enrolled were lower than expected. Also, the distribution of the $\operatorname{IgD}$ staining was nonhomogeneous across the sections in $9 / 40$ of the patients $(23 \%)$. Some MSG biopsies had been performed after the lymphoma was diagnosed. Although all patients were naive for B cell depletion therapy when the biopsy was performed, 2 more patients received chemotherapy (cyclophosphamide, doxorubicin, vincristine, prednisone) before the MSG biopsy was performed, and that might have influenced our results. It is still unclear whether GC formation is characterized best by the functional or morphological features ${ }^{20}$. Our study evaluates only the morphology of the cellular infiltrates, and AID expression analysis might have provided additional information.

Our study indicates that the GC-like structures seen in H\&E staining seem to be represented by various subtypes of $\mathrm{CD} 21+$ staining patterns. Although we were unable to reveal an association among the presence of GC-like structures, monoclonal B cell infiltration, and lymphoma development, the detection of identical B cell clones in MSG and lymphoma suggest an association between antigen-mediated clonal selection and lymphoma development.

\section{ACKNOWLEDGMENT}

We thank Tom Børge Johanessen (Cancer Registry of Norway), Øyvind Molberg (Rikshospitalet), Kjell Haaland (Helse Førde), Halvor Nygård (Lillehammer), Øyvind Midtvedt (Rikshospitalet), Maud-Kristine Aga (Ålesund Sykehus), Erik Rødevand (St. Olavs Hospital), Johan G. Brun (Haukeland Universitetssykehus), Kjell Kjellevold (Stavanger University Hospital), and Geirmund Myklebust (Sørlandet Sykehus) for help with clinical data; Dagny Ann Sandnes for cutting the minor salivary gland tissue sections; and Marianne Eidsheim for double-staining of the minor salivary gland sections.

\section{REFERENCES}

1. Jonsson R, Vogelsang P, Volchenkov R, Espinosa A, Wahren-Herlenius M, Appel S. The complexity of Sjögren's syndrome: novel aspects on pathogenesis. Immunol Lett 2011;141:1-9. 
2. Jonsson R, Theander E, Sjostrom B, Brokstad K, Henriksson G. Autoantibodies present before symptom onset in primary Sjögren's syndrome. JAMA 2013;310:1854-5.

3. Cruz-Tapias P, Rojas-Villarraga A, Maier-Moore S, Anaya JM. HLA and Sjögren's syndrome susceptibility. A meta-analysis of worldwide studies. Autoimmun Rev 2012;11:281-7.

4. Ice JA, Li H, Adrianto I, Lin PC, Kelly JA, Montgomery CG, et al. Genetics of Sjögren's syndrome in the genome-wide association era. J Autoimmun 2012;39:57-63.

5. Lessard CJ, Li H, Adrianto I, Ice JA, Rasmussen A, Grundahl KM, et al. Variants at multiple loci implicated in both innate and adaptive immune responses are associated with Sjögren's syndrome. Nat Genet 2013;45:1284-92.

6. Yao Y, Liu Z, Jallal B, Shen N, Ronnblom L. Type I interferons in Sjögren's syndrome. Autoimmun Rev 2013;12:558-66.

7. Jonsson MV, Skarstein K. Follicular dendritic cells confirm lymphoid organization in the minor salivary glands of primary Sjögren's syndrome. J Oral Pathol Med 2008;37:515-21.

8. Kapsogeorgou EK, Christodoulou MI, Panagiotakos DB, Paikos S, Tassidou A, Tzioufas AG, et al. Minor salivary gland inflammatory lesions in Sjögren syndrome: do they evolve? J Rheumatol 2013;40:1566-71.

9. Salomonsson S, Jonsson MV, Skarstein K, Brokstad KA, Hjelmstrom P, Wahren-Herlenius M, et al. Cellular basis of ectopic germinal center formation and autoantibody production in the target organ of patients with Sjögren's syndrome. Arthritis Rheum 2003;48:3187-201.

10. Szodoray P, Alex P, Jonsson MV, Knowlton N, Dozmorov I, Nakken B, et al. Distinct profiles of Sjögren's syndrome patients with ectopic salivary gland germinal centers revealed by serum cytokines and BAFF. Clin Immunol 2005;117:168-76.

11. Reksten TR, Jonsson MV, Szyszko EA, Brun JG, Jonsson R, Brokstad KA. Cytokine and autoantibody profiling related to histopathological features in primary Sjögren's syndrome. Rheumatology 2009;48:1102-6.

12. Jonsson MV, Skarstein K, Jonsson R, Brun JG. Serological implications of germinal center-like structures in primary Sjögren's syndrome. J Rheumatol 2007;34:2044-9.

13. Reksten TR, Johnsen SJ, Jonsson MV, Omdal R, Brun JG, Theander E, et al. Genetic associations to germinal centre formation in primary Sjögren's syndrome. Ann Rheum Dis 2013;73:1253-8.

14. Theander E, Vasaitis L, Baecklund E, Nordmark G, Warfvinge G, Liedholm R, et al. Lymphoid organisation in labial salivary gland biopsies is a possible predictor for the development of malignant lymphoma in primary Sjögren's syndrome. Ann Rheum Dis 2011;70:1363-8.

15. Bombardieri M, Barone F, Humby F, Kelly S, McGurk M, Morgan $\mathrm{P}$, et al. Activation-induced cytidine deaminase expression in follicular dendritic cell networks and interfollicular large B cells supports functionality of ectopic lymphoid neogenesis in autoimmune sialoadenitis and MALT lymphoma in Sjögren's syndrome. J Immunol 2007;179:4929-38.

16. Le Pottier L, Devauchelle V, Fautrel A, Daridon C, Saraux A, Youinou P, et al. Ectopic germinal centers are rare in Sjögren's syndrome salivary glands and do not exclude autoreactive B cells. J Immunol 2009;182:3540-7.

17. Cappione A 3rd, Anolik JH, Pugh-Bernard A, Barnard J, Dutcher P, Silverman $\mathrm{G}$, et al. Germinal center exclusion of autoreactive B cells is defective in human systemic lupus erythematosus. J Clin Invest 2005;115:3205-16.

18. Pascual V, Liu YJ, Magalski A, de Bouteiller O, Banchereau J, Capra JD. Analysis of somatic mutation in five B cell subsets of human tonsil. J Exp Med 1994;180:329-39.

19. Vinuesa CG, Sanz I, Cook MC. Dysregulation of germinal centres in autoimmune disease. Nat Rev Immunol 2009;9:845-57.

20. Neyt K, Perros F, GeurtsvanKessel CH, Hammad H, Lambrecht BN. Tertiary lymphoid organs in infection and autoimmunity. Trends Immunol 2012;33:297-305.

21. Thaunat O, Nicoletti A. Comment on "Activation-induced cytidine deaminase expression in follicular dendritic cell networks and interfollicular large B cells supports functionality of ectopic lymphoid neogenesis in autoimmune sialoadenitis and MALT lymphoma in Sjögren's syndrome". J Immunol 2008;180:2007-8.

22. Zuckerman NS, Hazanov H, Barak M, Edelman H, Hess S, Shcolnik H, et al. Somatic hypermutation and antigen-driven selection of B cells are altered in autoimmune diseases. J Autoimmun 2010;35:325-35.

23. Theander E, Henriksson G, Ljungberg O, Mandl T, Manthorpe R, Jacobsson LT. Lymphoma and other malignancies in primary Sjögren's syndrome: a cohort study on cancer incidence and lymphoma predictors. Ann Rheum Dis 2006;65:796-803.

24. Johnsen SJ, Brun JG, Gøransson LG, Småstuen MC, Johannesen TB, Haldorsen K, et al. Risk of non-Hodgkin's lymphoma in primary Sjögren's syndrome: a population-based study. Arthritis Care Res 2013;65:816-21.

25. Ekstrom Smedby K, Vajdic CM, Falster M, Engels EA, Martinez-Maza O, Turner J, et al. Autoimmune disorders and risk of non-Hodgkin lymphoma subtypes: a pooled analysis within the InterLymph Consortium. Blood 2008;111:4029-38.

26. Voulgarelis M, Dafni UG, Isenberg DA, Moutsopoulos HM. Malignant lymphoma in primary Sjögren's syndrome: a multicenter, retrospective, clinical study by the European Concerted Action on Sjögren's Syndrome. Arthritis Rheum 1999;42:1765-72.

27. Isaacson PG. Update on MALT lymphomas. Best Pract Res Clin Haematol 2005;18:57-68.

28. Kuper-Hommel MJ, van Krieken JH. Molecular pathogenesis and histologic and clinical features of extranodal marginal zone lymphomas of mucosa-associated lymphoid tissue type. Leuk Lymphoma 2012;53:1032-45.

29. Sagaert X, De Wolf-Peeters C, Noels H, Baens M. The pathogenesis of MALT lymphomas: where do we stand? Leukemia 2007;21:389-96.

30. Streubel B, Huber D, Wohrer S, Chott A, Raderer M. Frequency of chromosomal aberrations involving MALT1 in mucosa-associated lymphoid tissue lymphoma in patients with Sjögren's syndrome. Clin Cancer Res 2004;10:476-80.

31. Zhou Y, Ye H, Martin-Subero JI, Gesk S, Hamoudi R, Lu YJ, et al The pattern of genomic gains in salivary gland MALT lymphomas. Haematologica 2007;92:921-7.

32. Nocturne G, Boudaoud S, Miceli-Richard C, Viengchareun S, Lazure T, Nititham J, et al. Germline and somatic genetic variations of TNFAIP3 in lymphoma complicating primary Sjögren's syndrome. Blood 2013;122:4068-76.

33. Nordmark G, Wang C, Vasaitis L, Eriksson P, Theander E, Kvarnstrom M, et al. Association of genes in the NF-kappaB pathway with antibody positive primary Sjögren's syndrome. Scand J Immunol 2013;78:447-54.

34. The Cancer Registry of Norway Institute of Population-based Cancer Research. Cancer Statistics 2011. [Internet. Accessed Aug 13, 2014]. Available from: www.kreftregisteret.no/en/ The-Registries/Cancer-Statistics

35. Vitali C, Bombardieri S, Jonsson R, Moutsopoulos HM, Alexander EL, Carsons SE, et al. Classification criteria for Sjögren's syndrome: a revised version of the European criteria proposed by the American-European Consensus Group. Ann Rheum Dis 2002;61:554-8

36. van Dongen JJ, Langerak AW, Bruggemann M, Evans PA, Hummel M, Lavender FL, et al. Design and standardization of PCR primers and protocols for detection of clonal immunoglobulin and T-cell

Personal non-commercial use only. The Journal of Rheumatology Copyright @ $\subset$ 2014. All rights reserved 
receptor gene recombinations in suspect lymphoproliferations: report of the BIOMED-2 Concerted Action BMH4-CT98-3936. Leukemia 2003;17:2257-317.

37. Berget E, Helgeland L, Molven A, Vintermyr OK. Detection of clonality in follicular lymphoma using formalin-fixed, paraffin-embedded tissue samples and BIOMED-2 immunoglobulin primers. J Clin Pathol 2011;64:37-41.

38. Stott DI, Hiepe F, Hummel M, Steinhauser G, Berek C. Antigen-driven clonal proliferation of B cells within the target tissue of an autoimmune disease. The salivary glands of patients with Sjögren's syndrome. J Clin Invest 1998;102:938-46.

39. Risselada AP, Looije MF, Kruize AA, Bijlsma JW, van Roon JA. The role of ectopic germinal centers in the immunopathology of primary Sjögren's syndrome: a systematic review. Semin Arthritis Rheum 2012;42:368-76.

40. Guerrier T, Le Pottier L, Devauchelle V, Pers JO, Jamin C, Youinou P. Role of Toll-like receptors in primary Sjögren's syndrome with a special emphasis on B-cell maturation within exocrine tissues. J Autoimmun 2012;39:69-76.

41. Jordan R, Diss TC, Lench NJ, Isaacson PG, Speight PM. Immunoglobulin gene rearrangements in lymphoplasmacytic infiltrates of labial salivary glands in Sjögren's syndrome. A possible predictor of lymphoma development. Oral Surg Oral Med Oral Pathol Oral Radiol Endod 1995;79:723-9.
42. Guzman LM, Castillo D, Aguilera SO. Polymerase chain reaction (PCR) detection of B cell clonality in Sjögren's syndrome patients: a diagnostic tool of clonal expansion. Clin Exp Immunol 2010;161:57-64.

43. Dong L, Chen Y, Masaki Y, Okazaki T, Umehara H. Possible mechanisms of lymphoma development in Sjögren's syndrome. Curr Immunol Rev 2013;9:13-22.

44. Bahler DW, Swerdlow SH. Clonal salivary gland infiltrates associated with myoepithelial sialadenitis (Sjögren's syndrome) begin as nonmalignant antigen-selected expansions. Blood 1998;91:1864-72.

45. Dong L, Masaki Y, Takegami T, Jin ZX, Huang CR, Fukushima T, et al. Clonality analysis of lymphoproliferative disorders in patients with Sjögren's syndrome. Clin Exp Immunol 2007;150:279-84.

46. Martin T, Weber JC, Levallois H, Labouret N, Soley A, Koenig S, et al. Salivary gland lymphomas in patients with Sjögren's syndrome may frequently develop from rheumatoid factor B cells. Arthritis Rheum 2000;43:908-16.

47. Croia C, Astorri E, Murray-Brown W, Willis A, Brokstad KA, Sutcliffe N, et al. Implication of Epstein-Barr virus infection in disease-specific autoreactive B cell activation in ectopic lymphoid structures of Sjögren's syndrome. Arthritis Rheumatol 2014 May 28 (E-pub ahead of print). 